\title{
Preliminary Adaptation of Criminal Attitudes to Violence Scale in Latvian and Russian
}

(DLaura Simane-Vigante Mg. psych.

Baltic International Academy, Latvia

1.simane@inbox.lv

\begin{abstract}
Violent offenders cause serious harm to their victims and affect the general well-being of the society. Many awareness and rehabilitation campaigns are introduced at the moment in Latvia that increases the necessity for adapted valid instruments in the native languages of the offenders. The aim of the research was to conduct a preliminary adaptation of Criminal Attitudes to Violence Scale (CAVS) in Latvian and Russian. CAVS has been designed to measure non-sexual physical violence of violent male offenders. Two groups ("Latvians" $N=200$ and "Russians" $N=200$ ) and four sub-groups of male offenders and non-offenders were formed. The translation of the scale in Latvian and Russian was organized separately and completed by back-translation method. Evaluation by both experts and a sample of target population was provided with the final Russian and Latvian versions of CAVS. Internal consistency of the items of the scale proved to be very good for all four sub-groups. Item analysis showed that both (Latvian and Russian) adapted CAVS versions work the best with the offender samples. There were three-factor structure reviled for both Latvian and Russian CAVS. The preliminary adaptation process has been completed and the further standardization process is intended.
\end{abstract}

Keywords: criminal attitudes, male offenders, physical violence, self-report measure, adaptation.

\section{Introduction}

Research of violence-related attitudes has become increasingly essential in the past few years, due to the global pandemic and other interconnected events that have increased violent actions or brought awareness to already existing levels of violence even in seemingly non-violent societies. Examples are police violence, racial violence, gender-based violence and most of all domestic violence (Proctor et al., 2020; Pillay, Barnes, 2020). There are a few very broad awareness-raising campaigns being conducted in Latvia on domestic violence that have been aimed at helping both victims of domestic violence and violent offenders with the aim to create a healthier society.

Violence is a broad term and there are many definitions and different theoretical models trying to find the best explanation. In most of the definitions, the reoccurring factor is that violence involves attempts, threats or actions of physical aggression. Violent behaviour could be motivated by extreme emotional states such as anger, frustration, rage or hate. In addition, criminal violence is theorized to be an illegal violent behaviour (Riedel, Welsh, 2015). It is a well-known and often researched fact that people's attitudes are strongly linked to their behaviour (Ajzen, 1991; Moore, Rothwell, Segrott, 2010; Seddig, Davidov, 2018). Attitudes in relation to criminal behaviour are definitely one of the main factors influencing criminal behaviour, its limits and the possibility of change. Generally speaking, criminal attitudes are "... thoughts, feelings and beliefs that are supportive of criminal conduct .... Antisocial attitudes are all about when it is alright to break the law" (Bonta, Andrews, 2016, 234).

Most researches on attitudes towards violence investigate the valence of attitudes from: (1) the viewpoint of the victim, thus how they perceive the violent actions that are brought upon them (Antai, Antai, 2009) or (2) the viewpoint of the society (Stickley et al., 2008). When implementing projects aimed at the rehabilitation and resocialization of violent offenders, it is necessary to research and analyse violence-related attitudes from the viewpoint of violent offenders that mostly are males (out of nine penitentiary institutions in Latvia, only one is for female prisoners). Assessment of criminal attitudes is one of the key components (alongside other psychological factors such as self-esteem) in programs and interventions aimed at reducing recidivism (Thapa, Brown, Skilling, 2020). To provide this assessment, valid measurement methods are needed.

In Latvia there is an issue regarding adapted research methods to measure violence-related attitudes. The author of the present article communicated with a staff member of The Methodological Department of University of Latvia (Faculty of Education, Psychology and Art) and received a confirmation that 
they were not able to locate any tests in their database measuring violence or aggression-related attitudes that were adapted in Latvian. This shows the necessity to adapt valid instruments measuring attitudes towards violence from the viewpoint of violent offenders.

The author together with colleagues started to research implicit attitudes towards violence of sentenced male offenders in the year 2013. In addition to different versions of Violence Implicit Association Test (IAT) there was a necessity for a valid self-report instrument measuring the same construct. Criminal Attitudes to Violence Scale (CAVS) was chosen (Polaschek, Collie, Walkey, 2004), which was originally developed in New Zealand. It is a 20 item, one-factor instrument developed specifically for the sample of male criminal offenders, because it is short and understandable for people of limited attention span and low education levels.

Although there are plenty of adapted and constructed self-report measures on aggression and violence in Russian, for example, the Aggression Questionnaire (AQ) (Buss, Perry, 1992; Jenikolopov, Cibulskij, 2007), the authors decided to conduct the adaptation process of CAVS in both Latvian and Russian at the same time. The decision was based on the author's research and clinical experience that the majority of inmates are Russian speaking, although there is no recent data available on how many Russian-speaking inmates are incarcerated in the prisons of Latvia. Even if the individual is fluent in Latvian, it is always easier to report his/her attitude in their mother tongue.

\section{The Original development and preliminary validation of CAVS}

D. Polaschek and colleagues conducted a wide analysis on self-report measurement methods for measuring attitudes towards violence and aggression. They concluded that there is a lack of research that investigates adult attitudes to aggression or violence in general, not to mention specially designed self-report measures for incarcerated males in particular (Polaschek, Collie, Walkey, 2004). Some scales (for example, Attitudes Towards Violence Scale (ATVS)), designed to measure general violence, were developed based on adolescent non- offender samples (Funk et al., 1999). D. Polaschek and colleagues aimed to develop a scale that: (1) is understandable for incarcerated males with low literacy levels and limited attention span; (2) is based on the offender's cultural background and subjective previous experiences; (3) was not correlated with a measure of social desirability bias; (4) would be able to separate violent from non-violent offenders. The authors argued that: “(..) measures of violence-related attitudes developed with violent prisoners would be better able to distinguish violent offenders from other career criminals, and would thus have more utility in a correctional setting than scales designed for non-offender populations" (Polaschek, Collie, Walkey, 2004, 495).

For the first study an item pool of 75 items was created that included attitudinal statements towards the content of non-sexual physically violent actions. The items were mostly drawn from authors' clinical experience as well as some items were added from the ATVS and EXPAGG-M (a scale for adult samples aimed at measuring aggressive attitudes was also tested on imprisoned offenders, here there was a correlation found to self-reported aggressive behaviour) (Archer, Haigh, 1997). All items were simply worded and written in the present tense. A five-point Likert scale was provided for each item from 5 (strongly agree) to 1 (strongly disagree). In this research 147 imprisoned male offenders were questioned and the results were correlated with the 6 out of 40 Balanced Inventory of Desirable Responding (BIDR) items (Paulhus, 1991) and The Physical Aggression Subscale of the Aggression Questionnaire (AQ-PA) (Buss, Perry, 1992). An exploratory factor analysis was used for the result analysis. The authors wanted to develop a brief single factor scale, as there was no theoretical or empirical evidence suggesting that a multi-factor scale would be a better solution. Principal component analysis with varimax rotation (PCA: VR) specified the factors to extract because of the unsuitable factor loadings and compliance with BIDR data. From the remaining 53 items, 20 items were chosen, which provided the best correlation with AQ-PA scores (0.48 and better) (Table 1).

The aim of the second study was to test on an independent sample (155 sentenced male prisoners), the results of CAVS were still internally reliable, related to physical aggression and uncorrelated with social desirability bias. Result of internal reliability $(0.95)$ was very high. CAVS mean score was not significantly different from the first study. There was a relationship found to AQ-PA8 and there was no relationship found to BIDR, as it was expected. D. Polaschek and colleagues (2004) concluded that CAVS is a valid measure that assesses criminal attitudes. Specifically, the term "criminal attitude" was used, because of the criminal content of the items, assuming the participants' involvement in a criminally violent lifestyle. 
Table 1

Final Factor Loadings for CAVS Items from Single Factor PCA

\begin{tabular}{|c|c|c|}
\hline Origins of the item & Item & $\begin{array}{l}\text { Factor } \\
\text { Loading }\end{array}$ \\
\hline \multirow{2}{*}{ Clinical experience } & If somebody insults me or my family, I feel better if I beat them up. & 0.8 \\
\hline & Lots of people are out to get you so you have to be violent. & 0.78 \\
\hline $\begin{array}{c}\text { EXPAGG } \\
\text { Instrumental beliefs } \\
\text { subscale }\end{array}$ & When I get violent, what I want most is to teach the other person a lesson. ${ }^{\mathrm{b}}$ & 0.77 \\
\hline \multirow{2}{*}{ Clinical experience } & Men should be allowed to sort their differences out by fighting. & 0.77 \\
\hline & If somebody puts me down, I feel like I have to fight them to get back my pride. & 0.74 \\
\hline $\begin{array}{l}\text { EXPAGG Expressive } \\
\text { beliefs subscale }\end{array}$ & $\begin{array}{l}\text { The best thing about being violent is that it gets my anger out of my } \\
\text { system. }^{c}\end{array}$ & 0.72 \\
\hline Clinical experience & Fighting between men is normal. & 0.72 \\
\hline $\begin{array}{c}\text { EXPAGG } \\
\text { Instrumental beliefs } \\
\text { subscale }\end{array}$ & After a fight I feel happy if I won and depressed if I lost. ${ }^{\text {b }}$ & 0.71 \\
\hline \multirow{2}{*}{ Clinical experience } & Some people have to be treated roughly because they lack feelings that can be hurt. & 0.71 \\
\hline & My loyalty to my friends or gang is more important than avoiding violence. & 0.69 \\
\hline $\begin{array}{c}\text { EXPAGG } \\
\text { Instrumental beliefs } \\
\text { subscale }\end{array}$ & I am more likely to be violent when another person shows me up in public. ${ }^{\mathrm{b}}$ & 0.69 \\
\hline \multirow{2}{*}{ Clinical experience } & The best lesson a man can teach his son is how to fight. & 0.68 \\
\hline & It is important to fight when's your gang's honour is threatened. & 0.67 \\
\hline \multirow{2}{*}{$\begin{array}{c}\text { EXPAGG } \\
\text { Instrumental beliefs } \\
\text { subscale }\end{array}$} & I believe that you have to use violence to get through to some people. ${ }^{b}$ & 0.67 \\
\hline & $\begin{array}{l}\text { The best thing about being violent is that it makes the other person get into } \\
\text { line. }^{\text {b }}\end{array}$ & 0.67 \\
\hline Clinical experience & When your main business is crime, being violent is just part of the job. & 0.67 \\
\hline \multirow[t]{2}{*}{ ATVS } & $\begin{array}{l}\text { It's necessary to carry a gun or a knife if you live in a rough } \\
\text { neighbourhood. }{ }^{\text {a }}\end{array}$ & 0.67 \\
\hline & If a person hits you, you have to hit them back. ${ }^{\text {a }}$ & 0.66 \\
\hline \multirow{2}{*}{ Clinical experience } & If I assault or rob someone, the chances are I'll get away with it. & 0.64 \\
\hline & Violence is an important part of my culture, even if it is against the law. & 0.62 \\
\hline
\end{tabular}

${ }^{a}$ ATVS (Funk et al., 1999)

${ }^{b}$ EXPAGG Instrumental beliefs subscale (Archer, Haigh, 1997)

${ }^{\circ}$ EXPAGG Expressive beliefs subscale (Archer, Haigh, 1997)

The aim of the present research is to conduct preliminary adaptation of criminal attitudes to violence scale in Latvian and Russian.

\section{Methodology}

The research questions were set:

1. Does the language validated CAVS version in Latvian and Russian present the item content correctly?

2. Does the language validated CAVS version in Latvian and Russian properly carry out the construct of the scale?

3. Is the Latvian and Russian CAVS still measuring attitudes towards physical non-sexual violence accurately?

4. How well the items of the language validated CAVS versions in Latvian and Russian fit together with other items?

5. Do the Latvian and Russian CAVS perform differently on the samples of offenders and nonoffenders?

6. What is the factor structure of Latvian and Russian CAVS? 
Participants. To adapt CAVS in Latvian and Russian four subsamples were considered:

1. Latvians $(\mathrm{N}=200)$. Sub-group "Offenders LAT" consisted of 86 male prisoners (aged 19-72; $M d n=33.5 ; S D=11.05$ ) incarcerated in two penitentiary institutions in Latvia. Sub-group "NonOffenders LAT" consisted of 114 never before sentenced males (aged 18-73, $M d n=28.5 ; S D=12.93$ ).

2. Russians ( $\mathrm{N}=200)$. Sub-group "Offenders RUS" consisted of 54 male prisoners (aged 18-62; $M d n=38 ; S D=11.2$ ) incarcerated in two penitentiary institutions in Latvia. Sub-group "Non-Offenders RUS" consisted of 146 never before sentenced males (aged 18-75, $M d n=44.5$; $S D=14.13)$.

The participants were informed that the assessment was conducted under conditions of strict anonymity. The offender's sub-samples in particular were informed that the data will be used only for research purposes and anonymity and that confidentiality is guaranteed.

Instrument. Criminal Attitudes to Violence Scale (CAVS) (Polaschek, Collie, Walkey, 2004).

Procedure. The author followed the general guidelines for adaptation of the test described in the literature (Rascevska, 2005; Boateng et al., 2018), after obtaining an official written permit from the original author to adapt CAVS in Latvian and Russian. The original author also provided the whole packet of CAVS that included the test itself as well as administration and scoring guidelines. Content analysis was done on the items of CAVS, especially paying attention to the cultural factors, because crime culture in Latvia and New Zealand differs significantly.

\section{$\underline{\text { Translation and language validation }}$}

The translation in both languages was organized separately and completed by back-translation method.

CAVS translation in Latvian. Three English teachers, who were native Latvians, were asked to translate CAVS in Latvian. Then the translations were interchanged and translated back into English. Afterwards each item was discussed separately by the teachers and a forensic psychologist (expert) and the best version of the item was chosen. The first draught of the translated scale was given to a sample of 5 male students to fill out and comment on each item, corrections were then made accordingly.

CAVS translation in Russian. CAVS translation was done as a seminar assessment for $4^{\text {th }}$ year Psychology undergraduate students in Baltic International Academy. A group of native Russian speaking students with good English skills were formed and they translated CAVS into Russian, exchanged the translations and translated it back to into English. Together with a Russian native psychology supervisor (expert) they discussed each item and concluded the best version of the scale. A group of 5 Russian native male participants were formed. They filled in the scale and gave their view of each of the topics, corrections were then made accordingly.

Since then, six research studies have been conducted (Simane-Vigante, Plotka, Blumenau, 2018; SimaneVigante, Plotka Blumenau, 2020) on a sample of offenders and non-offenders using the preliminary linguistically adapted CAVs, each time supplying an evaluation of the target population (violent male offenders) and making corrections accordingly. After the last research, the Latvian and Russian version of the scale was approved and ready for the psychometric evaluation process.

\section{Results and Discussion}

Descriptive statistics. Analysis of descriptive statistics was conducted for each general group of Latvians and Russians as well as sub-groups of offenders and non-offenders, to check the item properties. There is a formal normal distribution of the data, although there are also many outliers evident. Figures 1-3 show the distribution of the responses for the items in the Latvian group and sub-groups. It is visible that Latvian CAVS work much better (no outliers and extremes are visible) on the offender's sub-group, as it was originally thought to be (Polaschek, Collie, Walkey, 2004). The content of the items with the most outliers and extremes is discussed in Table 2. Some of the content was slightly changed in the process of language validation from the original (Table 1) due to cultural and other factors. 
Table 2

The content of "questionable" items

\begin{tabular}{|c|c|c|c|}
\hline Language & $\begin{array}{c}\text { Item } \\
\text { number }\end{array}$ & Linguistically validated item content & In English \\
\hline \multirow{2}{*}{ 㿣 } & Q3 & Daudzi cilvēki paši “uzprasās" uz vardarbību & $\begin{array}{l}\text { Many people "ask for" violence } \\
\text { themselves }\end{array}$ \\
\hline & Q20 & $\begin{array}{l}\text { Vardarbība ir svarīga manas kultūras daḷa, pat, ja } \\
\text { tas ir pretlikumīgi }\end{array}$ & $\begin{array}{l}\text { Violence is an important part of } \\
\text { my culture, even if it is against } \\
\text { the law }\end{array}$ \\
\hline \multirow{3}{*}{ 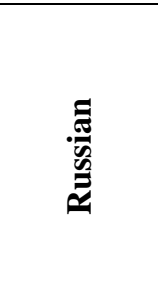 } & Q7 & $\begin{array}{c}\text { Проявление насилия позволяет мне дать волю } \\
\text { своему гневу }\end{array}$ & $\begin{array}{l}\text { Being violent lets me unleash } \\
\text { my anger }\end{array}$ \\
\hline & Q8 & $\begin{array}{c}\text { Лучший урок, который мужчина может } \\
\text { преподать своему сыну - научить его драться }\end{array}$ & $\begin{array}{l}\text { The best lesson a man can teach } \\
\text { his son is how to fight }\end{array}$ \\
\hline & Q20 & $\begin{array}{c}\text { Насилие является важной частью моей } \\
\text { культуры, даже если оно противоречит } \\
\text { закону }\end{array}$ & $\begin{array}{l}\text { Violence is an important part of } \\
\text { my culture, even if it is against } \\
\text { the law }\end{array}$ \\
\hline
\end{tabular}

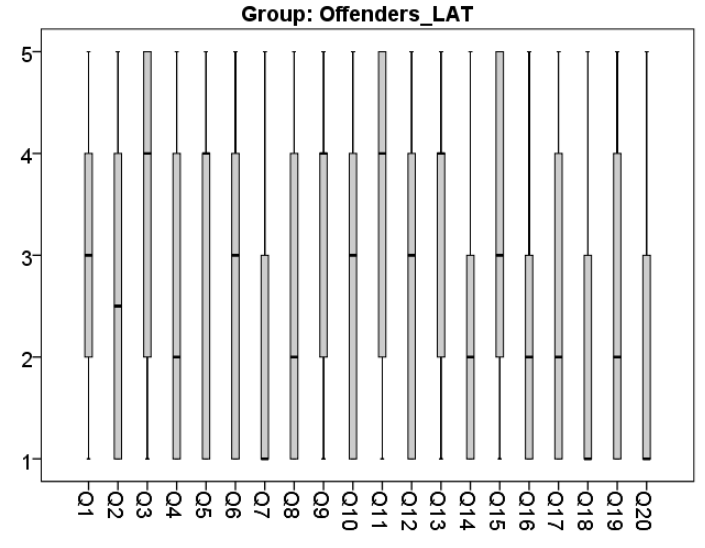

Figure 1. Boxplot of Latvian sample sub-group (offenders).

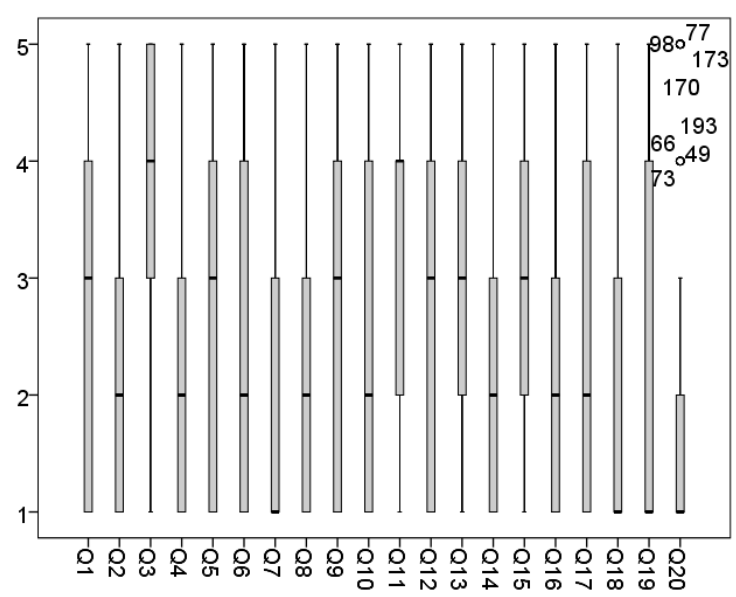

Figure 3. Boxplot of general Latvian sample.

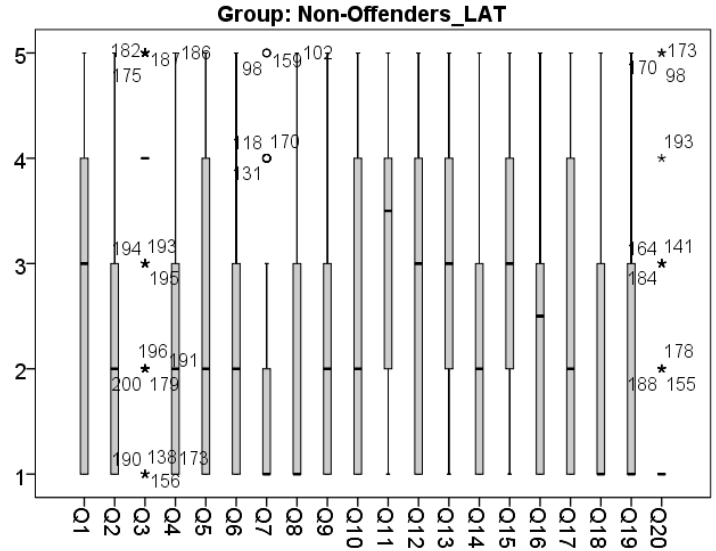

Figure 2. Boxplot of Latvian sample sub-group (Nonoffenders).

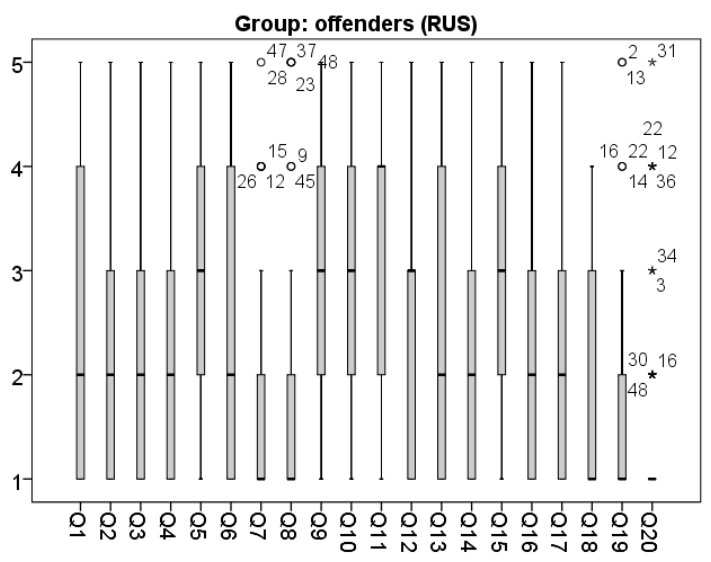

Figure 4. Boxplot of Russian sample sub-group (offenders) 


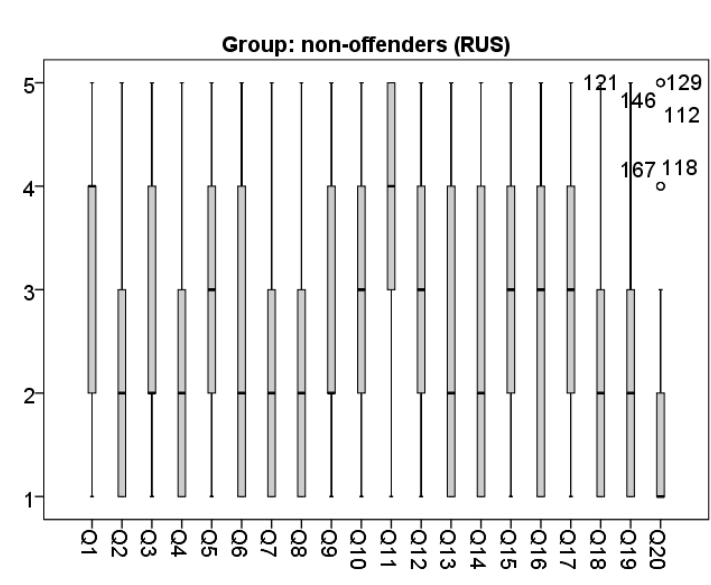

Figure 5. Boxplot of Russian sample sub-group (Non-offenders).

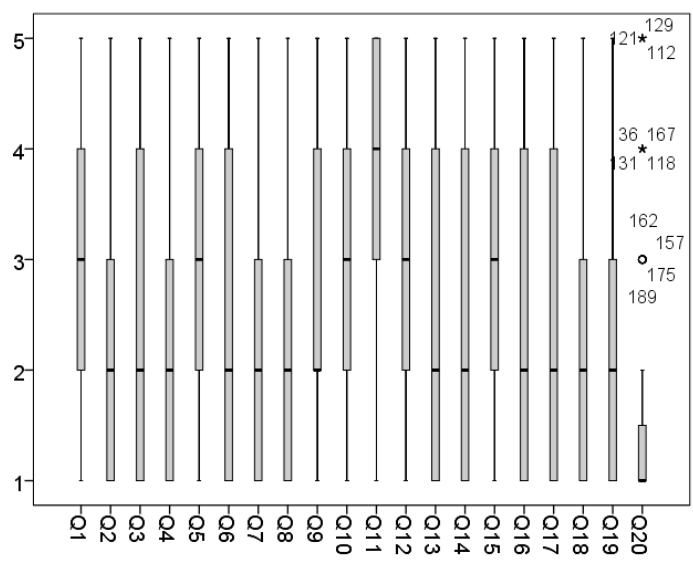

Figure 6. Boxplot of general Russian sample.

Analysis of internal consistency. To answer the second research question, a reliability analysis was performed. Cronbach's alpha reliability analysis showed results varying from good to excellent.

1. For the group "Latvians" Cronbach's alpha was 0,87 (sub-group "Offenders LAT" 0,9; sub-group "Non-Offenders LAT" 0,8).

2. For the group "Russians" Cronbach's alpha was 0,83 (sub-group "Offenders RUS" 0,85; sub-group "Non-Offenders RUS" 0,81).

Item analysis (Item difficulty, item discrimination). To answer the first, third and fourth research questions, item analyses were conducted.

Item difficulty. If the items of the test are formed on a sequential scale (answers vary in a range of 3 or more, such as the Likert scale), then the difficulty index is calculated as the arithmetic mean of the items $\mathrm{M}_{\mathrm{j}}$. As, in this case, there are 5 values - from 1(strongly disagree) to 5 (strongly agree), then $\mathrm{M}_{\mathrm{j}}$ should be in the range of 1.4-4.2 (Rascevska, 2005). Group "Latvians" $\mathrm{M}_{\mathrm{j}}$ is in the range of 1.59-3.69; for the group "Russians" $\mathrm{M}_{\mathrm{j}}$ is in the range of 1.45-3.60, which is acceptable in both cases. The same is seen for the four sub-groups, except item 20 for the Latvian sub-group "non-offenders" $M_{j}=1.33$. Both item 20 and the Latvian non-offender sample already raised some questions (Figure 2) and will be examined further.

Item discrimination. According to E. Cristobal and colleagues (2007), the items are considered acceptable if the item total correlation score is more than 0.30 (Cristobal, Flavián, Guinalíu, 2007). However, in some cases (for example, exploratory studies) 0.20 is an acceptable value (also called as workable). Items with scores below 0.3 can be looked at, but not necessarily deleted, as the reliability score does not improve at all, if the items are deleted. Latvian non-offender's subgroup has more unacceptable items, but as it was reviled before (Figure 2), CAVS were designed for the population of offenders (Polaschek, Collie, Walkey, 2004) and the psychometric properties of the adapted instrument (Latvian version) prove that the scale works a lot better on the population of offenders.

In the Russian group the corrected item total correlation score is unacceptable (below 0.30) in all three cases (results of the group and subgroups) for item 20 (Figures 4 - 6). This item was discussed by the participants the most. Some of them did not understand the meaning of culture, some did not understand if there is a kind of violence that is not against the law. Instead of deleting the item all together, a content analysis of this question was carried out by a Russian native forensic expert and an organization of another focus group of five Russian inmates sentenced for violent crimes, and a decision was made to change the wording of the item to: "Насилие является важной частью моейжизни, несмотря на то что оно противоречит закону" (in English: Violence is an important part of my life, despite the fact that it is against the law). In this case the word "culture" is replaced with "life" and the second part of the sentence is rewarded. Moreover, the same change was done for Latvian CAVS, as it was evident that the item properties are questionable for non-offenders, which impacted the data of the whole sample (Figure 2, Figure 3). Further procedure of standardization is necessary to decide either this item should be left or removed permanently. 
As the $r$ Item-total correlation score for none of the items of the general samples of Latvian and Russian population is below 0.2 , it has been decided to move forward to factor analyses using the data of the whole sample of Russians $(\mathrm{N}=200)$ and Latvian $(\mathrm{N}=200)$ participants. Particular limitations of the sample are discussed further.

Factor analysis. Using factor analysis (Principal Component Method, Rotation Varimax, $\mathrm{KMO}=0.88$ $(\mathrm{LAT}) ; \mathrm{KMO}=0.79$ (RUS), Bartlett's Test of Sphericity: (RUS) $\chi^{2}(171, N=200)=866, \mathrm{p}<0.001$ and (LAT) $\chi^{2}(171, N=200)=1084$, total explained variance $40 \%$, three factors $)$ applied to the scale of non-sexual physical violence CAVS method, three factors were obtained for each group. The first factor included almost identical items for both groups. The factors were preliminary named: RUS "Anger induced physical violence", "Violence benefit and necessity index" and "General violent attitude and belief index". For Latvian CAVS: "Anger induced physical violence", "Violence justification index" and "General violent attitude and belief index".

Limitations. The sample size is the most essential limitation in this study. Although it can be argued, because it has been said that at least 10 participants are the minimum for each item. As CAVS has only 20 items, 200 participants in each group could be enough. Some other authors have also said that 200-300 participants (minimum) are enough for factor analyses (Boateng et al., 2018). However, there are many researchers that would oppose the sample. It is essential to thoroughly plan the time and recourses that each research is going to take. As there were two adaptations done at the same time, the process was even more difficult. The sample of violent male offenders is not easily accessible and the topic of physical violence is not always well received by the targeted population. It is planned to conduct further standardization of the test in a much larger sample of the targeted population.

The sample of offenders was not limited to violent offenders only, due to the limited accessibility of the target population. Perhaps that is the reason Russian CAVS results for the sample of offenders showed uneven tendencies. In the standardization of CAVS, only violent male offenders should be carefully chosen and other demographics should be taken in to account as well as the relationship with a similar adapted version.

\section{Conclusions}

- Criminal attitudes are thoughts, feelings and beliefs supporting criminal conduct. Thus, if a person thinks that the most effective way to resolve a conflict or make someone respect him is by physically harming or threatening to harm another person, he is likely to act violently in a state of intense negative emotions, for example, anger or hate.

- Criminal attitudes towards violence measurement methods are needed to predict the risk of repetitive violent behaviour, as well as measuring the effectiveness of the rehabilitation program or intervention.

- It is necessary to adapt the instrument in both Latvian and Russian languages to be used for the sample of violent male offenders.

- The translation in both languages was organized separately and completed by back-translation method.

- Evaluation by both experts and target population was provided with the final Russian and Latvian versions of CAVS.

- Internal consistency of the items of the scale proved to be very good for all four sub-groups.

- Item analysis showed that both (Latvian and Russian) adapted CAVS versions work the best with the offender samples.

- There were three-factor structures reviled for both Latvian and Russian CAVS.

- It is planned to conduct further standardization of the test on a much larger sample of the target population.

- The preliminary adaptation of Latvian and Russian CAVS is completed and the instrument can be used to measure non-sexual physical violence of violent male offenders.

- CAVS can be used to track the progress of rehabilitation programs of violent male offenders. 


\section{Acknowledgments}

I want to thank Dr.psych. Irina Plotka for her scientific supervision and insight during the past ten years of my academic career, Dr. sc. Ing. Nina Blumenau for her input and help in data analyses during the beginning stages of CAVS adaptation. I would like to thank former students for helping to obtain the data and in the process of language validation: Maksim Cuikov, Alena Ivanova, Alina Tersukova, Natalja Kovalenko, Ina Sermolina and Sandra Poga. I would like to thank my colleagues of the Resocialization department of Riga Central Prison, especially Lilija Indrane, Anete Pope and Vitalijs Nedbalskis for volunteering in helping me to gather the final data needed for the adaptation. I also want to thank all participants for taking part in the adaptation of CAVS.

\section{Bibliography}

1. Ajzen I. (1991). The Theory of Planned Behavior. Organizational Behavior and Human Decision Processes, 50(2), 179-211. doi: 10.1016/0749-5978(91)90020-T

2. Antai D., Antai J. (2009). Collective Violence and Attitudes of Women toward Intimate Partner Violence: Evidence from the Niger Delta. BMC International Health and Human Rights, 9(12). doi: 10.1186/1472-698X-9-12

3. Archer J., Haigh A. (1997). Beliefs about Aggression among Male and Female Prisoners. Aggressive Behaviour, 23(6), 405-415. doi: 10.1002/(SICI)1098-2337(1997)23:6<405::AID$\mathrm{AB} 1>3.0 . \mathrm{CO} ; 2-\mathrm{F}$

4. Boateng G.O., Neilands T.B., Frongillo E.A., Melgar-Quiñonez H.R., Young S.L. (2018). Best Practices for Developing and Validating Scales for Health, Social, and Behavioral Research: A Primer. Frontiers in Publick Health, 6(149). doi: 10.3389/fpubh.2018.00149

5. Bonta J., Andrews D.A. (2016). The Psychology of Criminal Conduct (6 $6^{\text {th }}$ ed.) New York: Routledge. doi: 10.4324/9781315677187

6. Buss A.H., Perry M. (1992). The Aggression Questionnaire. Journal of Personality and Social Psychology, 63(3), 452-459.

7. Cristobal E., Flavián C., Guinalíu M. (2007). Perceived E-Service Quality (PeSQ): Measurement Validation and Effects on Consumer Satisfaction and Web Site Loyalty. Managing Service Quality, 17(3), 317-340. doi: 10.1108/09604520710744326

8. Funk J.B., Elliott R., Urman M.L., Flores G.T., Mock R.M. (1999). The Attitudes Towards Violence Scale: A measure for adolescents. Journal of Interpersonal Violence, 14(11), 1123-1136. doi: 10.1177/088626099014011001

9. Jenikolopov S.N., Cibulskij N.P. (2007). Psikhometricheskiy analiz russkoyazychnoy versii Oprosnika diagnostiki agressii A. Bassa i M. Perri [Psychometric analysis of the Russianlanguage version of the Aggression Questionnaire by A. Bass and M. Perry]. Psychological Journal, 28(1), 115-124. (in Russian)

10. Moore G.F., Rothwell H., Segrott J. (2010). An Exploratory Study of the Relationship between Parental Attitudes and Behaviour and Young People's Consumption of Alcohol. Substance Abuse Treatment, Prevention, and Policy, 5(6). doi: 10.1186/1747-597X-5-6

11. Paulhus D.L. (1991). Measurement and control of response bias. In J.P. Robinson, P.R. Shaver, L.S. Wrightsman (Eds.), Measures of personality and social psychological attitudes. New York: Academic Press, 1, 17-59.

12. Pillay A.L., Barnes, B.R. (2020). Psychology and COVID-19: Impacts, Themes and Way Forward. South African Journal of Psychology, 50(2), 148-153. doi: 10.1177/0081246320937684

13. Polaschek D.L.L., Collie R.M., Walkey F.H. (2004). Criminal Attitudes to Violence: Development and Preliminary Validation of a Scale for Male Prisoners. Aggressive Behaviour, 30(6), 484-503. doi: 10.1002/ab.20081

14. Proctor S.L., Li K., Chait N., Owens C., Sang E., Proper G., Ogundiran D. (2020). Preparation of School Psychologists to Support Black Students Exposed to Police Violence: Insight and Guidance for Critical Training Areas. Contemporary School Psychology. doi: 10.1007/s40688020-00317-6

15. Rascevska M. (2005). Psihologisko testu un aptauju konstruēšana un adaptācija [Construction and adaptation of psychological tests and surveys]. Rīga: Raka (in Latvian). 
16. Riedel M., Welsh W. (2015). Criminal Violence: Patterns, Explanations, and Prevention (4th ed.). Oxford University Press.

17. Seddig D., Davidov E. (2018). Values, Attitudes toward Interpersonal Violence and Interpersonal Violent Behavior. Frontiers in Psychology, 9. doi: 10.3389/fpsyg.2018.00604

18. Simane-Vigante L., Plotka I., Blumenau N. (2018). Research of the Relationship of Criminal Violence, Adult Attachment Styles and Personality Traits of Violent Male Offenders. In V. Dislere (Ed.), The Proceedings of the 9th International Scientific Conference Rural Environment, Education, Personality (REEP), 11. Jelgava: Latvia University of Life Sciences and Technologies, 166-174. doi: 10.22616/REEP.2018.015

19. Simane-Vigante L., Plotka I., Blumenau N. (2020). The relationship between implicit and explicit attitudes towards criminal violence and attachment styles. In V. Dislere (Ed.), The Proceedings of the 9th International Scientific Conference Rural Environment, Education, Personality (REEP), 13. Jelgava: Latvia University of Life Sciences and Technologies, 150-161. doi: 10.22616/REEP.2020.018

20. Stickley A., Kislitsyna O., Timofeeva I., Vågerö D. (2008). Attitudes toward Intimate Partner Violence against Women in Moscow, Russia. Journal of Family Violence, 23, 447-456. doi: 10.1007/s10896-008-9170-y

21. Thapa S., Brown S.L., Skilling T.A. (2020). The Relationship Between Self-Esteem, Gender, Criminal Attitudes, and Recidivism in a Youth Justice Sample. Criminal justice and behaviour. Advanced online publication. doi: 10.1177/0093854820977577 